\title{
Crossing Lilium Orientals of different ploidy creates Fusarium-resistant hybrid
}

\author{
Sixiang Zheng ${ }^{1}$,Hongzhi $\mathrm{Wu}^{2}$, Yan $\mathrm{Zhao}^{2}$,Feihu Liu ${ }^{3}$ \\ 1 Horticultural Research Institute, Guizhou Academy of Agricultural Science, Guiyang \\ 550006, China
}

2The Gardening Department of Horticulture College, Yunnan Agriculture University

Kunming 650201, China;

3The Life Science College of Yunnan University Kunming 650091, China;

\begin{abstract}
Oriental hybrid lily is of great commercial value, but it is susceptible to Fusarium disease that causes a significant loss to the production. A diploid Oriental hybrid resistant to Fusarium, Cai-74, was diploidized from triploid obtained from the offspring of tetraploid (from 'Star Fighter') and diploid ('Con Amore', 'Acapulco') by screening the hybrids of different cross combinations following inoculating Fusarium oxysporum to the tissue cultured plantlets in a greenhouse. By analyzing saponins content in bulbs of a number of lily genotypes with a known Fusarium resistance, it was found that the mutant Cai-74 had a much higher content of saponin than its parents. Highly resistant wild L. dauricum had the highest level $(4.59 \mathrm{mg} / \mathrm{g})$, followed by the resistant Cai-74 with $4.01 \mathrm{mg} / \mathrm{g}$. The resistant OT cultivars 'Conca d'or' and 'Robina' had a higher saponins content $(3.70 \mathrm{mg} / \mathrm{g})$ and $2.83 \mathrm{mg} / \mathrm{g}$, than the susceptible Oriental
\end{abstract}


lily cultivars 'Sorbonne', 'Siberia' and 'Tiber'. The hybrid Cai-74 had a different karyotype compared with the normal Lilium Oriental hybrid cultivars. The results suggested that Cai-74 carries a chromosomal variation correlated to Fusarium resistance. Cai-74 might be used as a genetic resource for breeding of Fusarium resistant cultivars of Oriental hybrid lilies.

Keywords: Fusarium resistance; polyploid diploidization; Karyotype variation; Lilium Oriental; Saponin

\section{Introduction}

As one of the four cut flowers of most importance, lily is of great commercial value. However, lily is susceptible to diseases, especially to the fungal diseases. Among the fungal diseases of lily, the basal decay (bulb root) caused by single infection of Fusarium oxysporum or compound infection of Fusarium oxysporum with other pathogens is the most serious and common one (Löffler et al., 1996; Lawson et al., 1996; Linderman, 1981). Fusarium is a type of soil-borne fungus that causes serious diseases in many crops (Windels, 2000; Nelson et al., 1981), and the specialized form that infects lily is Fusarium oxysporum f. sp. lilii. That causes lily bulb browning and rotting from the basal disc, and then involves the whole bulb by the late stage and destroys the bulbs and leads to a great loss (McRae, 1988).

Owing to the large size, bright color, pleasant scent and peculiar posture of the flower, Lilium Oriental is widely favored, but it is susceptible to diseases. The investigation done by Straathof et al.(1994) showed that the Lilium Asiatic hybrids 
showed the strongest resistance, followed by the Lilium longiflorum, while the Lilium Oriental was the weakest type, and no species or cultivars immune to Fusarium has been found up to now. Therefore, how to get the Fusarium-resistant mutants is of great value for breeding of lily and its production, especially for the Lilium Oriental that lacks inherent resistant gene. In the practice of lily breeding, Löffler (1996) found that the pathogen Fusarium had no adaptation to the resistant hosts, which therefore brings a possibility for breeding of new lily cultivars with persistent resistance to Fusruium. The correlation of antifungal effects and the accumulation of total saponins from in tissue cultures plants has been shown in several studies (Soetan et al., 2006; Rosca-Casian et al., 2007; Rodriguez et al., 2007). Saponin content could be an indicator for the degree of Fusarium resistance in Lilium (Curir et al., 2003). In the experiment, Fusariumresistant mutants were found among the hybrids of Lilium Oriental of different ploidy and they would be used as gene resource for the Fusarium-resistant breeding of Lilium Oriental. This paper introduced the results of a test done to the hybrids for the Fusarium resistance and the variations in saponin content and in karyotype.

\section{Materials and methods}

\subsection{Materials}

The highly resistant wild species 'L dauricum' and the susceptible Oriental Lilium cultivars 'Sorbonne', 'Siberia', 'Tiber' and the resistant OT cultivars 'Concad'orr', 'Robina' were used for the test of saponin content. The follow materials were used for Fusarium-inoculation (Fusarium oxysporum f. sp. lilii) in a greenhouse all belonged to 
the group of Lilium Oriental, including the diploid cultivars, tetraploid clones from somatic induction of cultivars, hybrids of $2 n \times 1 n$ gametes and hybrids of individuals in different ploidy (Table 1). Among the materials, Cai-74 and its female parent SF4n-11 and the male parent $\mathrm{YH}$ were also used for the test of saponin content in the bulb scales; Cai-74 was used for karyotype identification.

\subsection{Fusarium-inoculation and resistance identification}

Since the susceptibility to Fusarium decreases gradually as the growth of bulbed plants, it is best to test the disease-resistance by inoculating Fusarium at the stage of young plants (Straathof et al., 1997). The suspension of Fusarium oxysporum f. sp. lilii was prepared at the concentration of $1.0 \times 10^{6}$ spores per milliliter that could cause the disease. The tissue cultured lily plantlets (with small bulb) were planted in the humus soil in a greenhouse and were inoculated with the suspension for three times. For the first two inoculations, the plantlets were injured by pricking and sprayed with the suspension at 20-day interval. A direct spray of suspension onto the plantlets did the third inoculation.

The death criterion of lily plants was set as that the plants wilted off and the scales decayed and scattered. The dead plants were counted every 30 days after the first inoculation, and the bulbs of plants alive were harvested 150 days after the first inoculation when the final survival plants were counted. The resistance of the tested materials to Fusarium was identified based on the death rate of the lily plantlets and the harvested bulbs. 


\subsection{Determination of saponins content in scales}

\subsubsection{Establishment of a standard curve}

The standard solution for saponin test was prepared by weighing $3.60 \mathrm{mg}$ yam (Dioscorea batatas) saponin standard (purity> 99.9\%, Sigma, USA) into a $50 \mathrm{ml}$ volumetric flask and dissolved in a small amount of methanol, and then fixed up to 50 $\mathrm{ml}$ using methanol. Aliquots of $0.2,0.3,0.5,0.7,0.9,1.1$ and $1.3 \mathrm{ml}$ of standard solution (three duplicates for each point) were taken into $25 \mathrm{ml}$ test tubes respectively and evaporated to dryness in a water bath. Each tube was then added by $5 \mathrm{ml}$ perchloric acid $(70 \%-72 \%)$, stoppled tightly, reacted in a 55 water bath for $20 \mathrm{~min}$, and the reaction was terminated by putting the tubes in icy water. Absorbance of the reaction solutions was read at $408 \mathrm{~nm}$ by a spectrophotometer (UV1600), using perchloric acid as the reference to calibrate the instrument. A standard curve was set up using the concentration of saponin as the abscissa and the absorbance as the ordinate, and a linear regression equation was derived from the standard curve.

\subsubsection{Determination of saponins content in lily scales}

The fresh lily scales, washed in running water and dripped off the surface water, were dried in an oven at 40 until constant weight. The dried scales were ground into powder of 40-mesh fineness to prepare samples for saponin extraction. $0.750 \mathrm{~g}$ (DW) scale powder was weighted into a $50 \mathrm{ml}$ volumetric flask, $20 \mathrm{ml}$ petroleum ether with boiling point 60-90 was added, and was extracted for one hour under ultrasonic. The preparation was filtered, $20 \mathrm{ml}$ methanol was added to the leavings and was extracted for 
one hour again under ultrasonic, the extraction was fixed up to $50 \mathrm{ml}$ using methanol. Then $20 \mathrm{ml}$ methanol extraction was put in a tube and evaporated to dryness in a water bath. The leavings were washed into a separation funnel using $10 \mathrm{ml}$ distilled water and then extracted for four times using $10 \mathrm{ml}$ water-saturated $\mathrm{n}$-butanol each time. The $\mathrm{n}$ butanol extractions were mixed and condensed to dryness under decompression, and then was washed and volumed up to $10 \mathrm{ml}$ using methanol. This was the saponin extract.

The saponin extract of $0.3 \mathrm{ml}$ (three duplicates for each sample) was taken into a $25 \mathrm{ml}$ test tube and evaporated to dryness in water bath. Each tube was then added by 5 $\mathrm{ml}$ perchloric acid (70\%-72\%), stoppled tightly, reacted in a 55 water bath for $20 \mathrm{~min}$, and the reaction was terminated by putting the tube in icy water. Absorbance of the reaction solution was read at $408 \mathrm{~nm}$ by a spectrophotometer (UV1600), using perchloric acid as the reference to calibrate the instrument. The saponin content in lily scales $\left(\mathrm{mg} \mathrm{g}^{-1} \mathrm{DW}\right)$ was obtained by dividing the saponin content $(\mathrm{mg} / \mathrm{ml})$ in the extract that was calculated using the regression equation derived from the standard curve in part 1.3.1 with an index 1.8.

\subsection{Karyotype analysis and chromosome identification for lilies}

Root tips of lilies were treated with saturated p-dichlorobenzene for 10h and then fixed in Carnoy fixative (absolute ethyl alcohol: glacial acetic acid =1:1 in volume) for 10h. The fixed root tips, treated with $1 \mathrm{M} \mathrm{HCl}$ at 60 for $10 \mathrm{~min}$ for dissociation, were used to prepare chromosome slides by conventional squash technique, and the chromosomes were observed, counted and photographed under an optical microscope. 
The relative length and arm ratio of chromosomes were tested to at least five cells with intact metaphases, and the types of chromosomes were identified following the Levan's system. The karyotype was determined according to the criterion suggested by Stebbins (1971).

\section{Results and analysis}

\subsection{Fusarium resistance of the tested materials}

Lily plants showed different responses in greenhouse when inoculated with Fusarium oxysporum. Some strains such as ZY-3, T4L4-3 and ZS4-2 etc. showed disease symptom two weeks after inoculation and all plants died 60 days after inoculation. For other strains such as $\underline{\mathrm{SF} 4 \mathrm{n}}-11$ and T4L4-1, although the disease developed relatively slow and symptom appeared later, the growth of plants was stunted evidently showing the poor developed roots and the smaller bulbs than the healthy plants; bulb scales rotted and desquamated from the basal disc later on. However, strains such as SF4n-3, Cai-41 and Cai-74 showed no or light disease symptom with health leaves, roots and bulbs. In consequence, the survivability of the tested lily strains/cultivars was remarkably different (Table 2), which represented the difference in disease resistance. According to the data in Table 2, some strains in SF4n series (tetraploid clones from cultivar 'Star Fighter' via somatic induction) and in Cai series (hybrids of diploids $\times$ tetraploids) presented good resistance to Fusarium, while all other tested materials including diploid cultivars and hybrids of different cross types showed susceptible to the disease.The tested lily plants finished their growth season five 
months after the first Fusarium inoculation, when the bulbs were harvested. All the plants in most of the strains died at the end of the experiment, with the exception of strains in SF4n series and Cai Series that showed resistance to Fusarium in some extent with portions of bulbs harvested. Of the resistant strains, Cai-74 had the highest survivability and a bulb harvest percentage as high as $71.93 \%$, which implied a strongest resistance of Cai-74 to the disease (Table 2).

\subsection{Saponin determination}

\section{Calibration curve for diosgenin}

Diosgenin $\left(7.2 \times 10^{-2} \mathrm{mg} / \mathrm{ml}\right)$ prepared in methanol was used as standard for the saponins content. A calibration curve was prepared for quantitative determination of lily saponins. The amount of Diosgenin and its absorption measured with a spectrophotometer was used to determine the calibration curve. The absorption data for diosgenin and the calibration curve was shown in Fig. 4.

\subsection{Saponins content in the scale of Cai-74 and its parent}

A linear regression equation $\mathrm{Y}$ (saponin content, $\mathrm{mg} \mathrm{ml^{-1 }}$ ) $26.8038 \mathrm{x}$ (Absorbance $)+0.2764$ was derived from the standard curve set up in 1.3.1, with a determination coefficient 0.9984 . The saponin content in lily scales ( $\mathrm{mg} \mathrm{g}^{-1} \mathrm{DW}$ ) was calculated using the regression equation and the conversion index (see 2.3.2) as in Table 3. The Fusarium resistant Cai-74 had the highest saponins content of $3.78 \mathrm{mg} \mathrm{g}^{-1}$, significantly higher than that of its maternal parent SF4n-11 $\left(0.96 \mathrm{mg} \mathrm{g}^{-1}\right)$ and paternal parent $\mathrm{YH}\left(0.91 \mathrm{mg} \mathrm{g}^{-1}\right)$, but there was no difference in saponin content between the two parents, based on the statistical analysis using software SPSS. 


\subsection{Saponins content in lily bulbs of different genotypes}

In addition the total saponin content of lily genotypes was measured and compared with the known Fusarium-resistance, in order to find a correlation between these two characters. The bulb scale of tissue culture plants was used for the analysis of total saponins content. The wild species ' $L$ dauricum' is a highly resistant source to Fusarium oxysporum f.sp. lilii (Lim et al, 2003; Straathof et al, 1994). the saponin content determined by spectrophotometry showed that the highly resistant wild $L$. dauricum had the highest level $-4.59 \mathrm{mg} / \mathrm{g}$, followed by the resistant Cai- 74 with $4.01 \mathrm{mg} / \mathrm{g}$. The resistant OT cultivars 'Conca d'or' and 'Robina' had a higher saponins content $-3.70 \mathrm{mg} / \mathrm{g}$ and $2.83 \mathrm{mg} / \mathrm{g}$, than the susceptible Oriental lily cultivars 'Sorbonne', 'Siberia' and 'Tiber' (Table 4). These results suggest that total saponins content in lily bulbs could possibly used as indicator for Fusarium oxysporum resistance in lilies.

In this study we showed that total saponins in lily bulb are positively correlated with resistance to Fusarium oxysporum f.sp. lilii. When these findings are proved on a larger scale this could be a method to speed up the breeding for resistance to this disease.

\subsection{Cytological observation on hybrid progenies of different ploidy lilies}

By counting chromosome number, the results showed: small part were triploid and 
aneuploid plants, and mostly were tetraploids among the progeny plants of Lilium oriental $4 \mathrm{x} \times 4 \mathrm{x}$, besides some diploid plants, the progeny plants of Lilium oriental $3 \mathrm{x}($ sexual $) \times 2 \mathrm{x}$ were mostly the aneuploid, and the aneuploid plants had approximate diploid level; Among the progeny plants of Lilium oriental $3 \mathrm{x}$ (sexual) $\times 4 \mathrm{x}$ and $4 \mathrm{x} \times$ 2x, very small part was triploid plants, and mostly were diploid or aneuploid with approximate diploid level, which implied the possibility of polyploidy diploidization. And abnormal mitosis was observed such as chromosome bridge, multi-polar chromosome split, multi-polar nuclei split, two nuclei, etc., which suggested the opportunity to produce new variations.By Karyotype analysis with Stebbins standard, it was found: there was karyotype diversity among the progeny plants of Lilium oriental $3 \mathrm{x}$ (sexual) $\times 2 \mathrm{x}$ or $4 \mathrm{x}$. The variation of chromosome number and structure was observed.

\subsection{Karyotype of Cai-74 and its parent}

Cai-74 had a karyotype formula as $2 \mathrm{n}=2 \mathrm{x}=4 \mathrm{sm}+20 \mathrm{t}$, with the submetacentric centromere for chromosomes 1, 2, 3 and 4, and the telocentric centromere for the rest of chromosomes, showing an asymmetry coefficient of $79.25 \%$. The ratio in chromosome length of the longest and the shortest was 1.98 , and $91.6 \%$ of the chromosomes had the arm ratio greater than 2.0, which indicated that Cai-74 had a 3A karyotype(Fig. 1), rather than a 3B for normal lily cultivars.the mother plant was tetraploid $(2 n=4 x=48)$ had a karyotype formula as $2 n=4 x=8 m+20 s t+20 t$ with the metacentric centromere for chromosomes 1 and 3, the submetacentric centromere for chromosomes 6,7,8,9 and11, and the telocentric centromere for the rest of chromosomes, showing an asymmetry 
coefficient of $83.91 \%$.The ratio in chromosome length of the longest and the shortest was 2.91, which indicated that the mother plant had a 3B karyotype( Fig. 3). the father plant was $\operatorname{diploid}(2 \mathrm{n}=2 \mathrm{x}=24)$ had a karyotype formula as $2 \mathrm{n}=2 \mathrm{x}=2 \mathrm{~m}(1 \mathrm{SAT})+2 \mathrm{sm}+10 \mathrm{st}+10 \mathrm{t}$ with the metacentric centromere for chromosomes1, the submetacentric centromere for chromosomes 2, the subtelocentric centromere for 6,9,11and the telocentric centromere for the rest of chromosomes, showing an asymmetry coefficient of $81.10 \%$. The ratio in chromosome length of the longest and the shortest was 3.10, which indicated that the mother plant had a 3B karyotype(Fig. 2).

\section{Discussion}

\subsection{Fusarium-resistant mutant from crosses of Lilium Oriental of different ploidy}

The traditional methodology for breeding of disease-resistant cultivars was gene introgression, i.e. to transfer the resistant genes from the gene resources into the elite strains or excellent cultivars. For example, the resistant genes in Lilium dauricum that was known to have the strongest Fusarium-resistance were transferred into the cultivars of Lilium Oriental (Löffler et al., 1996; Lim et al., 2003). Alternatively, the Fusariumresistant genes were recombined into the hybrids by crossing the cultivars of Lilium Asiatic with that of Llilium Oriental (Schenk, 1990; Barba-Gonzalez, 2005; Lim et al., 2000). However, the previous studies showed that the Fusarium resistance of lily was a multi-gene character (Heusden et al., 2002), and the identification of the resistant genes was rather complicated, besides the Fusarium-resistant genes of lily mainly existed in the Lilium Asiatic, which made it necessary to do the distant crosses between different 
groups of lily. All these resulted in a very low efficiency in breeding of resistant cultivars by gene introgression strategy (Lim et al., 2003).

On the above argument, a new strategy for producing and screening the Fusariumresistant mutant of lily is of great importance for breeding of disease resistant cultivars and characterizing the resistant genes. In our experiment, quite many useful mutants, such as the Fusarium-resistant mutant Cai-74, were obtained by crossing the polyploids with diploids of Lilium Oriental. This maybe is a clue for breeding of Fusariumresistance in Lilium Oriental.

\subsection{Saponins content in scales and the Fusarium-resistance in lily}

The anti-fungal effect of saponins was observed in some plants (Woldemichael and Wink, 2001; Escalante et al., 2002; Iorizzi et al., 2002; Oana Rosca-Casian et al., 2007; Rodriguez et al., 2007). While the disease-resistant lily keeps a high level of saponin content to counteract pathogen infection by accelerating the synthesis of saponins or inhibiting the activity of enzyme that decomposes saponins (Weltring et al., 1997), by which to reduce the damage caused by pathogens. Thereby, under the same conditions, the disease-resistant species or cultivars have a higher content of saponins than the susceptible ones. The total content of saponins rather than the content of the active ingredients of saponin was used as an index to evaluate the resistance of lily to Fusarium in this study, owing to the facility and quickness for test and feasibility for utilization. This was verified by our experimental results.

\subsection{Possible causes of Fusarium-resistance presented in the mutant Cai-74}


The previous studies showed that all the species and cultivars in the group of Lilium Oriental lack Fusarium-resistance (Lim et al., 2003; Straathof et al., 1994), but some Fusarium-resistant mutant such as Cai-74 was obtained in our experiment. Cai-74, the hybrid of a tetraploid and a diploid, was supposed to be a triploid, but in fact, it is of diploid chromosomes, which was possibly resulted from the diploidization of polyploid. It is well known that the karyotype of lilies is a stable 3B, the parents of Cai-74, SF4n11 and $\mathrm{YH}$, and the other materials in our experiment had indeed a 3B karyotype (data not shown). However, the Fusarium-resistant mutant Cai-74 had a $3 \mathrm{~A}$ karyotype that revealed a variation in its chromosomal structure. The variation maybe resulted from the exchange and recombination of chromosome segments caused by the somatic crossover happened in the hybrid of tetraploid and diploid during the process of diploidization. This was very possible, a mechanism of the disease-resistant gene originated. On the other hand, Cai-74 had a much higher content of saponins in the scales than its parents, indicating a significant change in its metabolites, which also suggested the presentation of a novel gene or the new function of the primary gene (s). A research work targeting at the possible new gene (s) is being carried on.

\section{Acknowledgements}

The authors are grateful to the financial support from the National Key Technology

R\&D Program(Grant No.2007BAD45B01), and the Science and Technology Program of GuiZhou Province (Grant No.2009031,20094006,2008262,200880,TZJF-200827). 


\section{References}

Barba-Gonzalez R., 2005. The use of $2 \mathrm{n}$ gametes for introgression breeding in Oriental $\times$ Asiatic lilies. Dissertation, Wageningen University

Escalante A.M., Santecchia C.B., Lopez S.N., Gattuso M.A., Guttierez Ravelo A., Della Monache F., Gonzales Sierra M., Zacchino S.A., 2002. Isolation of antifungal saponins from Phytolacca tetramera, an Argentinean species in citric risk. J. Ethnopharmacol. 82, 29-34.

Heusden A.W., Jongerius M.C., van Tuyl J.M., Straathof Th.P., Mes J.J., 2002. Molecular Assisted Breeding For Disease Resistance in lily. Acta Horticulturae. International Society for Horticultural Science (ISHS), Leuven, Belgium: 572: 131-138

Iorizzi M., Lanzotti V., Ranali G., De Marino S., Zollo F. 2002. Antimicrobial furostanol saponins from the seeds of Capsicum annum L. var. Acuminatum. J. Agric. Food Chem. 50, 43104316

Lawson R.H., H.T. Hsu. 1996. Lily diseases and their control. Acta Horticulturae. 414, 175-187

Linderman RG. 1981. Fusarium diseases of flowering bulb crops, In: Nelson PE, Toussoun TA and Cook RJ (eds) Fusarium: Diseases, Biology and Taxonomy (pp) The Pennsylvania State University Press, University Park and London. 129-141

Lim J H., Rhee HK., Kim YJ., Lim KB., Tuyl JM. 2003. Resistance to Fusarium oxysporum f. sp. lilii in Lilium. Horticultural Science (ISHS), Leuven, Belgium, 620, 311-318

Lim K.B., Ramanna M.S., Van Tuyl J.M.. 2003. Homoeologous recombination in interspecific hybrids of Lilium. J. Breed, 35(1): 8-12

Lim K B, Van Tuyl J M, Khrustaleva L I, Karlov G I, De Jong J H. 2000. Introgression of interspecific hybrids of lily using genomic in situ hybridization (GISH). Acta Hort 508: 105-112

Löffler H.J.M., Meijer H., Straathof Th. P., Van Yuyl J.M. 1996. Segregation of Fusarium resistance in interspecific in cross between Longiflorum and Lilium Dauricum. Acta Hort. 414:203-208

McRae E.A. 1988. Fungus diseases. In: Lily Disease Handbook. North American Lily Society, 1318

Nelson P.E., Toussoun T.A. and Cook R.J. 1981. Fusarium: Diseases, Biology, and Taxonomy, The Pennsylvania State University Press, University Park.

Oana Rosca-Casian, Marcel Parvu, Laurian Vlase, Mircea Tamas. 2007. Antifungal activity of Aloe vera leaves. Fitoterapia. 78:219-222

Rodriguez D.J., Hernandez-Castillo D., Angulo-Sanchez J.L., Rodriguez-Garcia R.J., Quintanilla, A.V.,Lira-Saldivar R.H. 2007. Antifungal activity in vitro of Flourensia spp. extracts on Alternaria sp., Rhizoctonia solani, and Fusarium oxysporum. Industrial Crops and Products, 25:111-116

Ren, F.L., Qiu, C.G., Lian, Y. 2005. Extraction process of total saponins from Lilium brownii. J. Cent. South Uni. (Science and technology). 36 (1): 69-72.

Schenk P., 1990. Modern trends in lily breeding. In: Hayward A-F lilies and related plants. Supp Proc 5th Intl Lily Conf, London 124:41-49 
Stebbins G L. Chromosomal Evolution in Higher Plants. Lo-123ndon: Edward Arnold Ltd, 1971:72-123

Straathof T P, Loffler H J M. 1994. Screening for Fusarium resistance in seedling populations of Asiatic hybrid lily. Euphytica, 78 (1-2): 43-51

Straathof T P L filer H J M Linfield C A 1997 Breedingfor resistance to Fusarium oxysporum in flower bulbs Acta Horticulturae. $430 \quad 477-486$

Straathof, Th.P., Van Tuyl, J.M. 1994. Genetic variation in resistance to Fusarium oxysporum f.sp. lilii in the genus Lilium. Ann. appl. Biot., 125: 61-72.

Weltring K.M., Wessels J., Geyer R. 1997. Metabolism of the potato saponins a-chaconine and asolanine by Gibberella pilicaris. Pergamon, 46(6): 1005-1009

Woldemichael, G.M., Wink, M., 2001. Identification and biological activities of triterpenoid saponins from Chenopodium quinoa. J. Agric. Food Chem. 49, 2327-2332

Windels C E. 2000. Economic and social impact of Fusarium head blight: changing farms and rural communities in the northern Great plains, Phytopathology 90(1):17-21 


\section{Tables}

Table 1 Lily materials tested for their resistance to Fusarium oxysporum

\begin{tabular}{|c|c|c|}
\hline Type of materials & Materials & Description \\
\hline \multirow[t]{2}{*}{ Diploid cultivars } & Cor. Amor & Cor. Amore \\
\hline & $\underline{\text { Acapulco }}$ & $\underline{\text { Acapulco }}$ \\
\hline Tetraploid clones & $\underline{\text { SF4n series }}$ & Tetraploid plants from 'Star fighter' \\
\hline \multirow[t]{3}{*}{ Hybrids from 2 n female gametes } & $\underline{\mathrm{ZY}} 3$ & Cor. Amorex Acapulco \\
\hline & $\underline{\mathrm{ZY}} 4$ & Cor. Amorex Acapulco \\
\hline & $\underline{\mathrm{YH}}$ & $\underline{\text { Cor. Amorex }} \underline{\text { Acapulco }}$ \\
\hline \multirow[t]{2}{*}{ Hybrids of tetraploid clones } & $\underline{\text { T4L4 series }}^{*}$ & Hybrids of $\underline{\mathrm{T} 4 \times} \underline{\mathrm{L} 4}$ \\
\hline & $\underline{\text { SF4T4 series }}$ & Hybrids of SF4nx $\underline{\mathrm{T} 4}$ \\
\hline \multirow[t]{2}{*}{ Hybrids of diploids $x \underline{\text { tetraploids }}$} & $\underline{\mathrm{ZS} \text { series }}$ & Hybrids of $\underline{S F 4 n \times Z Y 17}$ \\
\hline & $\underline{\text { Cai series }}$ & Hybrids of $\underline{\mathrm{YH} \times \mathrm{SF} 4 \mathrm{n}}$ \\
\hline
\end{tabular}

*T4 - the tetraploid plants from cultivar 'Tiber', L4 - the tetraploid plants from cultivar 'Livarno'. 
Table 2 Survival plants investigated after inoculation of Fusarium oxysporum 


\begin{tabular}{|c|c|c|c|c|c|c|c|c|}
\hline \multirow[t]{2}{*}{$\begin{array}{l}\text { Type of } \\
\text { Materials }\end{array}$} & \multirow[t]{2}{*}{$\underline{\text { Materials }}$} & \multirow[t]{2}{*}{$\begin{array}{c}\text { Plants } \\
\text { inoculated }^{\mathrm{A}}\end{array}$} & \multicolumn{5}{|c|}{$\begin{array}{l}\underline{\text { Survivals investigated every } \underline{30} \text {-day }} \\
\text { after inoculation }\end{array}$} & \multirow{2}{*}{$\begin{array}{c}\text { Final } \\
\text { survivability } \\
\text { \& bulb } \\
\text { harvest } \\
(\mathrm{B} / \mathrm{A}, \underline{\%)}\end{array}$} \\
\hline & & & $\underline{30}$ & $\underline{60}$ & $\underline{90}$ & $\underline{120}$ & ${\underline{150^{\mathrm{B}}}}$ & \\
\hline \multirow[t]{2}{*}{$\begin{array}{l}\text { Diploid } \\
\text { cultivars } \\
\underline{4}\end{array}$} & $\begin{array}{l}\text { Cor. } \\
\text { Amore }\end{array}$ & $\underline{60}$ & $\underline{42}$ & $\underline{10}$ & $\underline{2}$ & $\underline{0}$ & $\underline{0}$ & $\underline{0}$ \\
\hline & Acapulco & $\underline{54}$ & $\underline{19}$ & $\underline{0}$ & $\underline{0}$ & $\underline{0}$ & $\underline{0}$ & $\underline{0}$ \\
\hline \multirow{3}{*}{$\begin{array}{l}\text { Tetraploid } \\
\text { clones }\end{array}$} & $\underline{\mathrm{SF}} 4 \mathrm{n}-3$ & $\underline{50}$ & $\underline{47}$ & $\underline{36}$ & $\underline{20}$ & $\underline{17}$ & $\underline{15}$ & $\underline{30.00}$ \\
\hline & $\underline{\mathrm{SF}} 4 \mathrm{n}-2$ & $\underline{49}$ & $\underline{49}$ & $\underline{28}$ & $\underline{14}$ & $\underline{14}$ & $\underline{14}$ & $\underline{28.57}$ \\
\hline & $\underline{\text { SF4n-11 }}$ & $\underline{57}$ & $\underline{45}$ & $\underline{15}$ & $\underline{9}$ & $\underline{0}$ & $\underline{0}$ & $\underline{0}$ \\
\hline \multirow{3}{*}{$\begin{array}{l}\text { Hybrids_from } \\
\underline{2 n \text { female }} \\
\text { gametes }\end{array}$} & $\underline{\mathrm{ZY}-3}$ & $\underline{46}$ & $\underline{20}$ & $\underline{0}$ & $\underline{0}$ & $\underline{0}$ & $\underline{0}$ & $\underline{0}$ \\
\hline & $\underline{\mathrm{ZY}-3}$ & $\underline{48}$ & $\underline{6}$ & $\underline{0}$ & $\underline{0}$ & $\underline{0}$ & $\underline{0}$ & $\underline{0}$ \\
\hline & $\underline{\mathrm{YH}}$ & $\underline{50}$ & $\underline{18}$ & $\underline{0}$ & $\underline{0}$ & $\underline{0}$ & $\underline{0}$ & $\underline{0}$ \\
\hline \multirow{4}{*}{$\begin{array}{l}\text { Hybrids of } \\
\text { tetraploids }\end{array}$} & $\underline{\text { T4L4-1 }}$ & $\underline{48}$ & $\underline{48}$ & $\underline{20}$ & $\underline{4}$ & $\underline{0}$ & $\underline{0}$ & $\underline{0}$ \\
\hline & $\underline{\text { T4L4-2 }}$ & $\underline{58}$ & $\underline{20}$ & $\underline{8}$ & $\underline{4}$ & $\underline{4}$ & $\underline{4}$ & $\underline{6.89}$ \\
\hline & $\underline{\mathrm{T} 4 \mathrm{~L} 4-3}$ & $\underline{38}$ & $\underline{12}$ & $\underline{0}$ & $\underline{0}$ & $\underline{0}$ & $\underline{0}$ & $\underline{0}$ \\
\hline & $\underline{\text { SF4T4-1 }}$ & $\underline{44}$ & $\underline{12}$ & $\underline{0}$ & $\underline{0}$ & $\underline{0}$ & $\underline{0}$ & $\underline{0}$ \\
\hline \multirow{6}{*}{$\begin{array}{l}\text { Hybrids of } \\
\underline{\text { diploids_X }} \times \\
\text { tetraploids }\end{array}$} & $\underline{\mathrm{ZS} 4-1}$ & $\underline{42}$ & $\underline{33}$ & $\underline{3}$ & $\underline{0}$ & $\underline{0}$ & $\underline{0}$ & $\underline{0}$ \\
\hline & $\underline{\mathrm{ZS} 4-2}$ & $\underline{45}$ & $\underline{25}$ & $\underline{0}$ & $\underline{0}$ & $\underline{0}$ & $\underline{0}$ & $\underline{0}$ \\
\hline & $\underline{\text { Cai-41 }}$ & $\underline{48}$ & $\underline{48}$ & $\underline{32}$ & $\underline{16}$ & $\underline{12}$ & $\underline{12}$ & $\underline{25.00}$ \\
\hline & $\underline{\text { Cai-46 }}$ & $\underline{57}$ & $\underline{52}$ & $\underline{37}$ & $\underline{9}$ & $\underline{5}$ & $\underline{0}$ & $\underline{0}$ \\
\hline & $\underline{\text { Cai-74 }}$ & $\underline{57}$ & $\underline{53}$ & $\underline{44}$ & $\underline{41}$ & $\underline{41}$ & $\underline{41}$ & $\underline{71.93}$ \\
\hline & $\underline{\text { Cai-29 }}$ & $\underline{40}$ & $\underline{28}$ & $\underline{6}$ & $\underline{1}$ & $\underline{1}$ & 1 & $\underline{2.50}$ \\
\hline
\end{tabular}




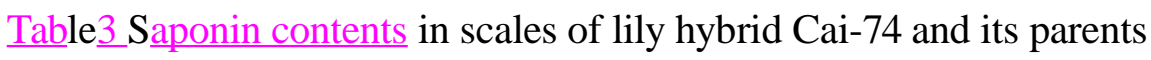

\begin{tabular}{|lcccc}
\hline Materials & \multicolumn{4}{l}{ Saponins content in scales $\underline{\left(\mathrm{mg} \mathrm{g}^{-1} \mathrm{DW}\right)}$} \\
\cline { 2 - 5 } & I & II & III & $\underline{\text { Mean }}$ \\
\hline$\underline{\text { Cai-74 }}$ & $\underline{3.80}$ & $\underline{3.78}$ & $\underline{3.76}$ & $\underline{3.78 \mathrm{a}}$ \\
$\underline{\mathrm{SF} 4 \mathrm{n}-11}$ & $\underline{0.98}$ & $\underline{0.95}$ & $\underline{0.96}$ & $\underline{0.96 \mathrm{~b}}$ \\
$\underline{\mathrm{YH}}$ & $\underline{0.92}$ & $\underline{0.90}$ & $\underline{0.90}$ & $\underline{0.91 \mathrm{~b}}$ \\
\hline
\end{tabular}

Table 4 Quantitative determination of lily saponin contents

\begin{tabular}{|c|c|c|c|c|c|c|}
\hline \multirow[t]{2}{*}{ Genotype } & \multirow{2}{*}{$\begin{array}{c}\text { Field } \\
\text { reaction to } \\
\text { Fusarium }\end{array}$} & \multicolumn{3}{|c|}{ Abs (408 nm) } & \multirow{2}{*}{$\begin{array}{c}\text { Saponins } \\
\text { content of } \\
\text { solution/ } \mu \mathrm{g} . \\
\mathrm{ml}-1\end{array}$} & \multirow{2}{*}{$\begin{array}{c}\text { Saponins } \\
\text { content of } \\
\text { bulb scale } \\
\text { / mg.g-1 }\end{array}$} \\
\hline & & $\mathrm{A} 1$ & $\mathrm{~A} 2$ & A3 & & \\
\hline Cai-74 & resistant & 0.2201 & 0.2357 & 0.2327 & 7.2130 & 4.01 \\
\hline Siberia & moderate & 0.1189 & 0.1005 & 0.1044 & 3.4599 & 1.92 \\
\hline Conca d'or & resistant & 0.2218 & 0.2185 & 0.1946 & 6.6605 & 3.70 \\
\hline Sorbonne & moderate & 0.1190 & 0.1307 & 0.1249 & 4.0677 & 2.26 \\
\hline Tiber & moderate & 0.0941 & 0.1035 & 0.1141 & 3.3364 & 1.85 \\
\hline Robina & resistant & 0.165 & 0.160 & 0.159 & 5.0988 & 2.83 \\
\hline L. dauricum & $\begin{array}{l}\text { Highly } \\
\text { resistant }\end{array}$ & 0.2567 & 0.2571 & 0.2770 & 8.2654 & 4.59 \\
\hline
\end{tabular}


Figures

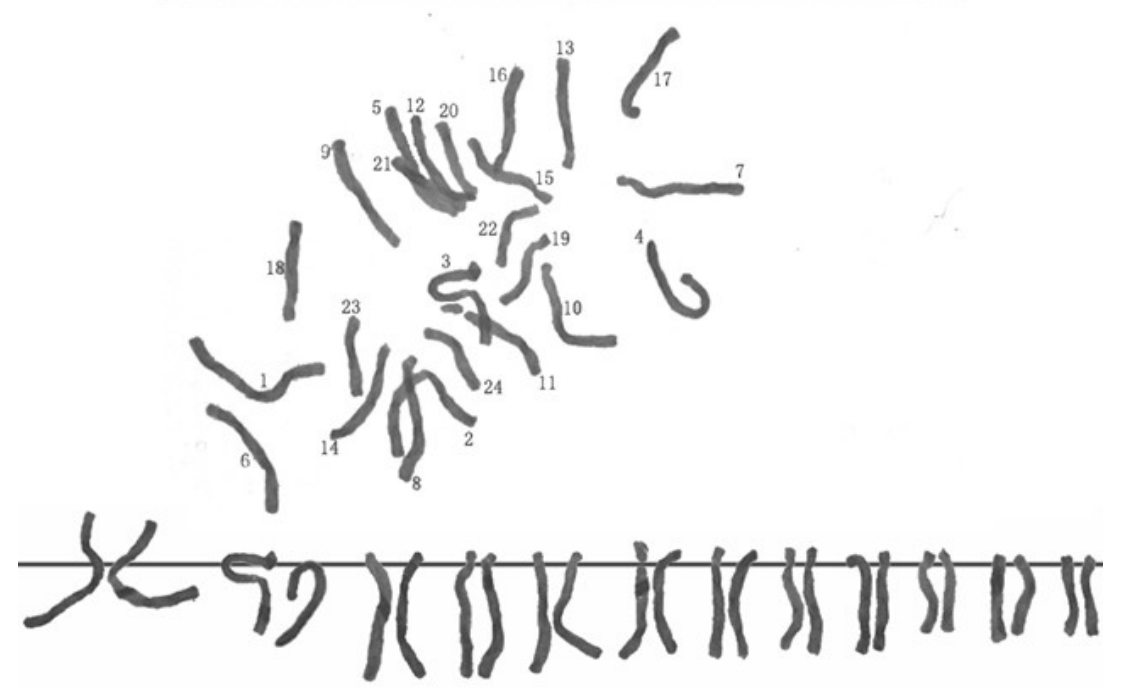

Fig. 1. Karyotype of Cai- 74 based on the metaphase chromosomes of root-tip cells 


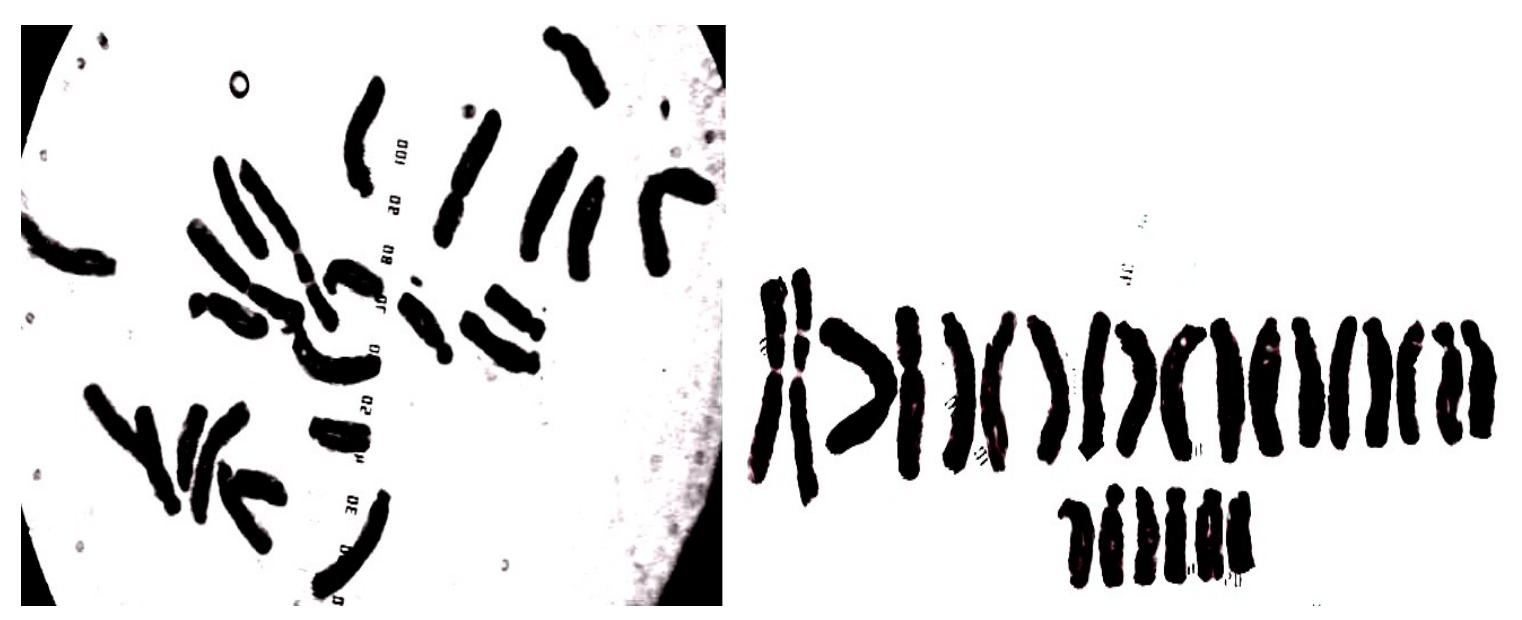

Fig. 2. Karyotype of male plant based on the metaphase chromosomes of root-tip cells_

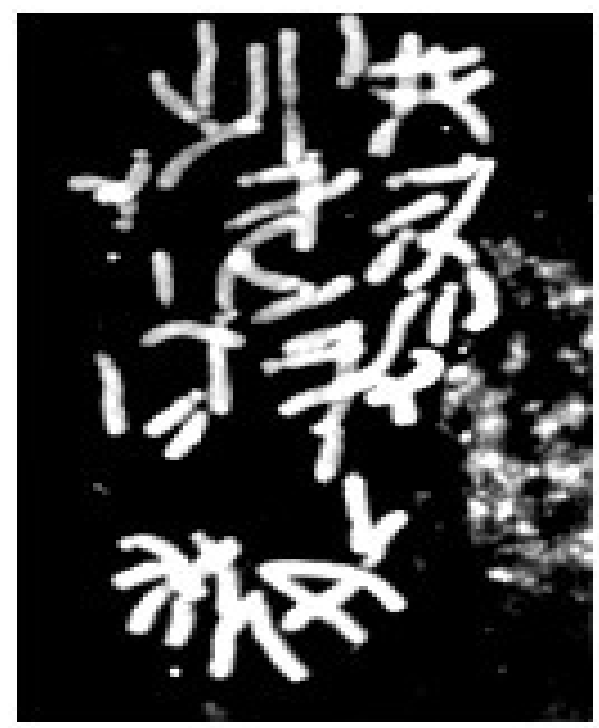

Fig. 3. Karyotype of female plant based on the metaphase chromosomes of root-tip cells 


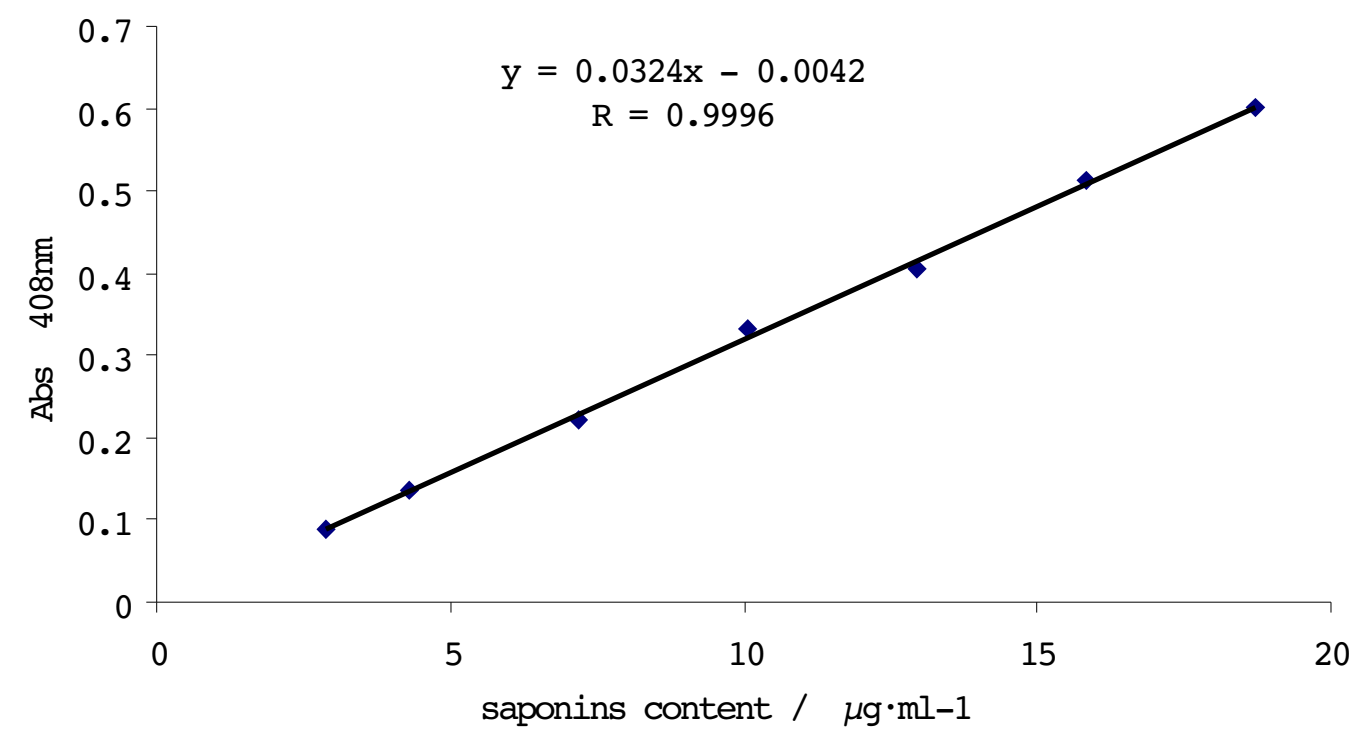

Fig. 4. The calibration curve of saponin content and absorbance.

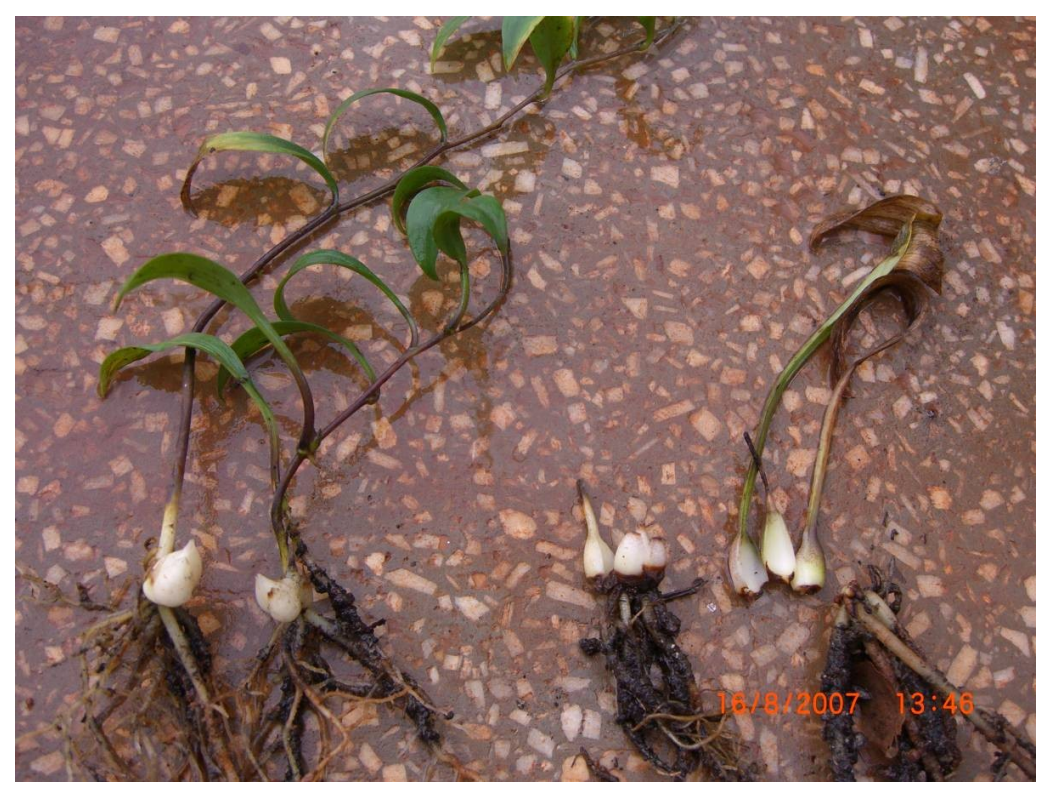

Fig.5. Plants of a resistant variant Cai-74 (left) and susceptible Oriental Lilium cultivar (right) after inoculation with Fusarium oxysporum f.sp. lilii. 